\title{
Feedback-based Learning Through Online Feedback Systems in Higher Education
}

Figas, Paula ${ }^{a}$; Bartel, Alexander ${ }^{a}$ and Hagel, Georg ${ }^{a}$

${ }^{a}$ Faculty of Computer Science, Kempten University of Applied Sciences, Germany

\begin{abstract}
From scientific research it is known that feedback from students to lecturers can positively influence teaching and learning in higher education. This involves both responses concerning the quality of teaching and to students' learning process. In courses with a large number of students it is challenging to receive individual feedback from all students, using the traditional method of oral feedback. One possible way is to use online feedback-systems. Through this, all students have the opportunity to express their opinion, requests or problems concerning the lecture in anonymous way, at any time. Furthermore, it allows the results to be discussed together in class. The paper deals with the issue of student feedback in higher education and presents an online feedback-system and its integration into the teaching process. In addition, the paper shows some empirical based experiences made with the feedback-system in three courses in a German University of Applied Sciences. It becomes visible that feedback-systems have the potential to improve the quality of teaching and make learning more interactive and student-oriented.
\end{abstract}

Keywords: Student Feedback; Feedback-based Learning; Higher Education. 


\section{Introduction}

It is known from scientific research that feedback plays a key role in learning success (Hattie \& Timperley, 2007; Sambell, 2011). This is why many studies focus on giving feedback to students. Besides, also for the lecturer, it is important to receive feedback from students to both constantly improve the quality of teaching and to assess the current understanding of students (Bergstrom, Karahalios \& Harris, 2011; Powney \& Hall, 1998; Ghilay \& Ghilay, 2015). In literature this kind of response is also called Learner to Educator Feedback or Student Feedback (Becker \& Butler, 2011). However, especially in courses with a large number of students it is challenging to receive oral feedback from all participants. Bergstrom, Karahalios \& Harris (2011) suggest that this is because students "often avoid volunteering information due to evaluation anxiety, a fear of being judged by others for making a mistake or being the focus of attention" (Bergstrom, Karahalios \& Harris, 2011, p. 627). This is not only the case when giving feedback concerning the quality of teaching but also in giving feedback to the own learning process, for example understanding barriers. One possible way to solve this problem is to support the courses with online feedback-systems. They give students the opportunity to express feedback in an anonymous way, at any time. Results can be discussed together in class (Bergstrom, Karahalios \& Harris, 2011). This type of teaching with online feedback-systems is also called Feedback-based Learning (FBL) (Ghilay \& Ghilay, 2015). There are already empirical studies illustrating the efficiency of such a learning approach (Ghilay \& Ghilay, 2015). In contrast, practical examples about how to implement feedback-systems in higher education are very rare in scientific literature. In the following, an online feedback-system and its integration in higher education will be presented.

\section{Online-Systems for Students' Feedback}

\subsection{Background: Student Feedback}

There is empirical evidence that student feedback can have positive influence on teaching and learning (Becker \& Butler 2011; Bergstrom, Karahalios \& Harris, 2011; Dwinell \& Higbee, 1993; Jena \& Chakraborty, 2014). For instance, asking for feedback shows students that their feelings and individual learning situations are taken seriously. Researchers already found out in 1993 that for students it is most important to know that their opinions are being heard (Dwinell \& Higbee, 1993, p. 999). Furthermore, it is possible for lecturers to get an impression of students' problems and current understanding and thereby "making student's thinking visible" (Etkina, 2000, p. 595). This is one of the most important strengths of such an approach, since it enables lecturers to address mentioned problems or questions regarding a certain lesson. It thereby means that teaching can be 
more adapted to individual learning situations, even in courses with a large amount of students. Besides, there is empirical evidence that feedback from students can also positively influence lecturer's motivation and their engagement in teaching (Jena \& Chakraborty, 2014) and through a structured feedback-system it is possible to stimulate students to reflect about their individual learning process (Lehmann, Söllner \& Leimeister, 2015).

Naturally, there are many different ways to receive student feedback (Powney \& Hall, 1998). A famous strategy is to use structured evaluations, especially at the end of the semester (Jena \& Chakraborty, 2014; Coffey \& Gibbs, 2001; Rindermann, 2001). An alternative is a continuous feedback during the entire semester (Etkina, 2000). This has the advantage that it is possible to react promptly and to immediately "work" with the gained insights. Besides, through online feedback-systems students can give feedback anonymously. Due to the fact that often only a few students ask questions in class (Bergstrom, Karahalios \& Harris, 2011) it thereby offers the opportunity to ask questions without fearing negative consequences.

\subsection{Feedback-Cycle}

According to the feedback-cycle of Hounsell (2003), the process can be divided into six steps: 1) Clarify context and focus, 2) devise a feedback strategy, 3) gather feedback, 4) analyze and interpret the data, 5) agree on action and 6) implement changes (Hounsell, 2003, p. 210).

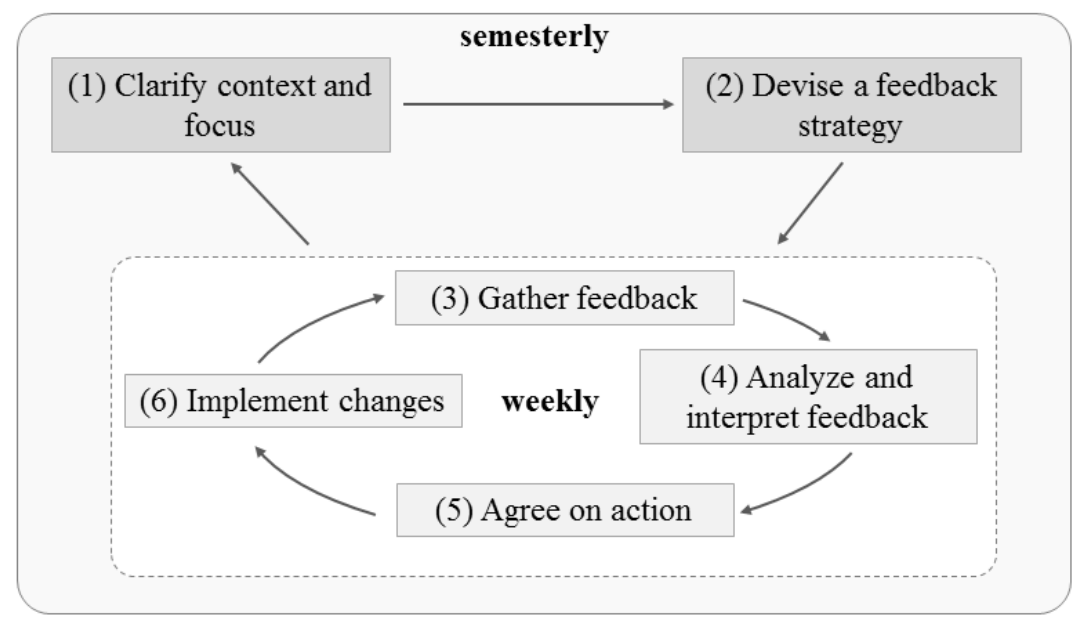

Figure 1. Adapted feedback-cycle inspired by Hounsell (2003) 
This model, which was initially created for evaluation contexts, can also serve to implement online-feedback systems. To have the opportunity to compare answers of students during the semester, it is appropriate to use the same context and focus, as well as the same feedback strategy for the whole semester (step 1 and 2) and then weekly iterate through the feedback-cycle, especially step 3-6 (see Figure 1). That means that gathered feedback can be weekly analyzed and implemented in teaching.

\subsection{Example}

Online-systems for students' feedback can look quite different. In the following an example of a German University of Applied Sciences will be presented to show how questions can look like. The underlying goal of the teaching concept is to both acquire feedback concerning the quality of teaching and the situation of students in an open and anonymous way and to have the ability to adapt teaching to meet the needs of the students. Based on the specific context a feedback strategy was designed. An online-based open questionnaire was established in Moodle where students have the possibility to write comments weekly, to ask questions and to give feedback to the lesson at any time. As Müller (2007) suggests, a combination of qualitative and quantitative responses is fruitful for a rich feedback. This is why the feedback-system consists of two parts, open questions and closed items. Open questions could be voluntarily answered. Questions were, for example:

- How do you feel about the last lesson?

- Do you have any whishes concerning the lecture?

- Do you have any questions concerning the last lessons or problems you would like to discuss?

In addition, closed items (7-point scale) basically refer to the learning situation of students, which all students in the course had to answer weekly in order to have access to the tasksheets of the week. Items were, beside others:

- How difficult did you find the last lesson?

- How much time did you spend to perform tasks of the last lesson?

- How difficult did you find the contents of the last lesson?

- In case you would write your exam tomorrow: How would you pass?

The online-questionnaire containing the questions presented above was given to students after every lesson and the resulting feedback was analyzed promptly before the next lesson. All comments in open questions were collected. Besides, the results of open questions closed questions were analyzed and presented in diagrams. Based on the gained insights the lecturer decides how to react to the results in the next lesson, for example to prepare further learning material, give more explanations or to apply different teaching strategies. Each lecture starts with referring to the recent feedback, presenting the results and implementing 
the actions that were planned before. For instance, the lecturer presents possible solutions, offers further learning material or follow-up explanations.

\section{Experiences and Evaluation}

The feedback-system was implemented in three different courses in a German University of Applied Sciences. All courses were held by the same lecturer and were about programming languages for first semester computer science students. Course I had 83 students and took place in winter semester 2014/15. Course II with 79 students took place in winter semester 2015/16 and course III with 80 students took place in winter semester 2016/17. In total 242 students participated in three course iterations.

\subsection{Qualitative Feedback}

Open-ended questions were on a voluntary basis. As could be seen in Table 1, the opportunity to give open feedback was used frequently by all semesters. The response was high; still it was different in the courses. The open answers can be divided into feedback concerning the quality of teaching and feedback concerning the individual learning situation. In total 267 responses were given in three courses.

Table 1: Amount of responses in open questions in all courses (I, II and III)

\begin{tabular}{lcccccc}
\hline & & I & II & III & Total \\
\hline $\begin{array}{l}\text { Feedback } \\
\text { concerning the } \\
\text { quality of teaching }\end{array}$ & Positive & 37 & 44 & 25 & \multirow{2}{*}{143} \\
\cline { 2 - 5 } $\begin{array}{l}\text { Feedback } \\
\begin{array}{l}\text { concerning the } \\
\text { individual learning } \\
\text { situation }\end{array}\end{array}$ & Hints & 8 & 19 & 17 & 9 & \multirow{2}{*}{124} \\
\cline { 2 - 5 } & Questions & 27 & 13 & 12 & \\
\cline { 2 - 5 } Total & Problems & 3 & 34 & 2 & 267 \\
\hline
\end{tabular}

Students' comments varied greatly. Most of the comments (143) refer to the quality of teaching. Open answers were for example "I really like the example you gave last lesson. NOW I understand!", or "Your explanation of polymorphism was too fast the last time!" Questions about the individual learning situation mainly refer to understanding problems and questions (in total 124). Students made examples with code, they asked simple understanding questions, for example "I still have some problems with inheritance and polymorphism". "Could you please explain the difference between getter and setter? Thanks!". Those hints, questions and problems were collected and discussed together in the next session. 


\subsection{Quantitative Feedback}

Quantitative feedback gives insights how students feel about their learning process. Results can be presented to students weekly, for instance with diagrams. Moreover, trends became visible when analyzing the diagrams and relating certain teaching units to learning contents. For instance, it became obvious when comparing the third, fourth and fifth teaching unit of the three semesters, that there is a considerably increase in perceived difficulty of the learning contents (see Figure 2). This finding further strengthens the results gained from the qualitative remarks of the students for these specific units. Having the possibility to compare three different semesters, a lecturer is able to create more profound ideas for longterm changes in learning activities which can more precisely show their effect on specific learning contents. Therefore these changes have the potential to positively influence the student's perceived difficulty of learning contents in a positive way. It is worth mentioning that basic changes of learning activities should only be realized after observing at least three different semesters. The heterogeneity of the students requires this period of time and prevents lecturers from well-meant actionism.

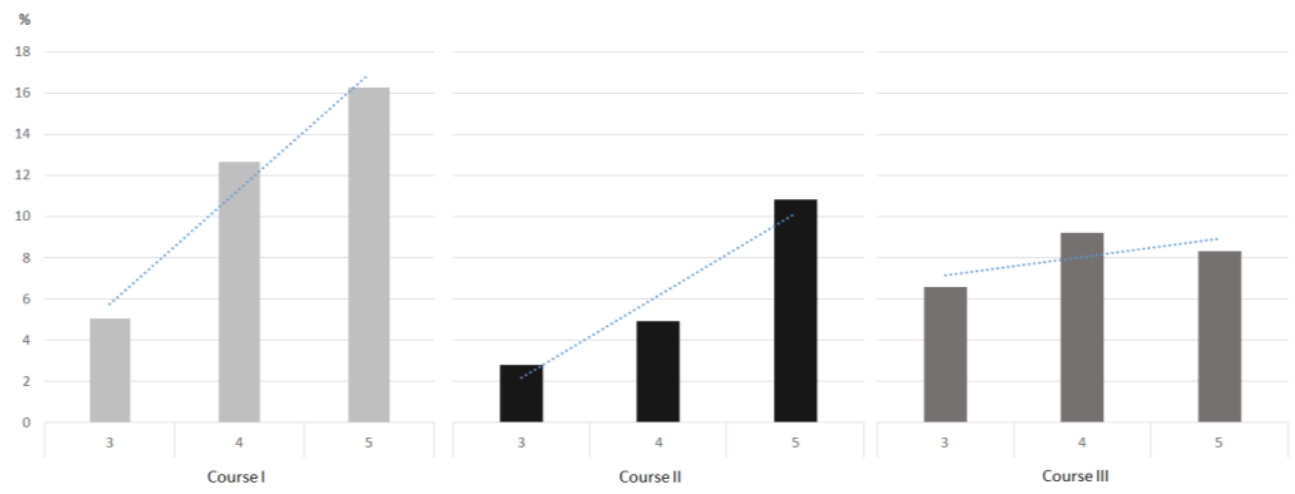

Figure 2. Feedback which indicates that difficulty is considered as high or very high. Regarding all courses (I, II and III) in three learning units (3, 4 and 5).

Nevertheless, collecting and comparing quantitative feedback data can serve as a valuable, non-exclusive, instrument in order to tackle students' problems. 


\subsection{Evaluation}

To get an impression how students rate the feedback-system an open question at the end of the semester was added: "How do you feel about the course in total, including the feedback-system?" Interestingly, a few students (13\%) stated that the feedback system had in their impression some negative aspects. For example, a student stated: "To be honest: To answer that questionnaire every week is annoying". Still, most of the students (78\%) said that it helped a lot to have the opportunity to ask questions any time. A student wrote: "I appreciate that you discuss all the questions together in class. I learned a lot through it". And: "More lecturers should use such anonymous feedback!". This shows that students have different opinions about the feedback-system. Interestingly, several students stated that they are normally afraid of asking questions in the lesson and that the feedback-system helped them to express their opinion anonymously.

\section{Conclusion and Outlook}

Online feedback-systems enable to get weekly feedback from students and enables lecturers to discuss results in class. This has several positive effects: students get an anonymous space to communicate with the lecturer; the lecturer gets feedback and knows how students consider themselves regarding their learning progress. Based on this the lecturer can adapt teaching. Experiences in higher education courses lead to the assumption that anonymity plays an important role in students feeling free to ask questions and criticize without fearing negative consequences. One of the most important aspects is that lecturers can discuss feedback at the next possible opportunity and to discuss questions and problems in class, thereby closing the "feedback loop" (Keane, 2005, p. 12). However, it must be noted, that such a feedback-system cannot be seen as alternative for direct feedback and interaction in class. It must rather be seen as assistance for communication. In summary it can be said that for those lecturers with large amounts of students, online-feedback systems can help to improve communication and lead to better, more individualized teaching. This paper showed one possibility to use an online feedback-system and gave some insights into students' view about it. Still, further work must be done to prove the efficiency and the impact which online feedback-systems have on learning success.

\section{Acknowledgments}

This work is part of the EVELIN project which is supported by the Bundesministerium für Bildung und Forschung with the project number 01PL12022C. 


\section{References}

Becker, B., \& Butler, O. (2011). Learner-to-Educator Feedback - Acquiescence Bias, Reliability and Learner Opinion. In International Conference on Engaging Pedagogy. Ireland.

Bergstrom, T., Harris, A., \& Karahalios, K. (2011). Encouraging Initiative in the Classroom with Anonymous Feedback. In Pedro Campos, Nicholas Graham, Joaquim Jorge, Nuno Nunes, Philippe Palanque, Marco Winckler (Ed.), IFIP Conference on HumanComputer Interaction (pp. 627-642).

Coffey, M., \& Gibbs, G. (2001). The Evaluation of the Student Evaluation of Educational Quality Questionnaire (SEEQ) in UK Higher Education. Assessment \& Evaluation in Higher Education, 26(1), 89-93.

Ditton, H. (2014). Feedback und Rückmeldungen: Theoretische Grundlagen, empirische Befunde, praktische Anwendungsfelder. Münster, New York and New York: Waxmann.

Dwinell, P. L., \& Higbee, J. L. (1993). Student's Perceptions of the Value of Teaching Evaluations, 76, 995-1000.

Etkina, E. (2000). Weekly Reports: A Two-Way Feedback Tool. Science Education, 84(5), 594-605.

Ghilay, Y., \& Ghilay, R. (2015). FBL: Feedback Based Learning in Higher Education. Higher Education Studies, 5(5), 1-10.

Hattie, J., \& Timperley, H. (2007). The Power of Feedback. Review of Educational Research, 77(1), 81-112.

Hounsell, D. (2003). The Evaluation of Teaching. In H. Fry, S. Ketteridge, \& S. Marshall (Eds.), A Handbook for Teaching \& Learning in Higher Education (pp. 200-212). London: Kogan Pape.

Jena, A. K., \& Chakraborty, P. (2014). Effect of Student Feedback on the Motivation of Indian University Teachers. Journal on Educational Psychology, 7(3), 23-31.

Keane, E. (2005). Obtaining Student Feedback on Teaching \& Course Quality. Centre for Excellence in Learning and Teaching, retrieved from http://www.nuigalway.ie/media/celt/files/coursedesign/

ReviewofTeachingEvaluationMethods.pdf.

Lehmann, K., Söllner, M., \& Leimeister, J. M. (2015). Der Wert von IT-gestütztem Peer Assessment zur Unterstützung des Lernens in einer universitären Massenlehrveranstaltung. In International Conference on Wirtschaftsinformatik.

Leibold, N., \& Schwarz, L. M. (2015). The Art of Giving Online Feedback. The Journal of Effective Teaching, 15(1), 34-46.

Powney, J., \& Hall, S. (1998). Closing the Loop: The Impact of Student Feedback on Students' Subsequent Learning: SCRE. 
Rindermann, H. (2001). Lehrevaluation: Einführung und Überblick zu Forschung und Praxis der Lehrveranstaltungsevaluation an Hochschulen mit einem Beitrag zur Evaluation computerbasierten Unterrichts. Landau: Verlag Empirische Pädagogik.

Sambell, K. (2011). Rethinking Feedback in Higher Education: An Assessment for Learning Perspective. The Higher Education Academy. Subject Centre for Education. Bristol. retrieved from https://www.plymouth.ac.uk/uploads/production/document/path/2/2729/Rethinking FeedbackInHigherEducation.pdf. 